\title{
A Study on the Drama Communication in the Post Stage Period
}

\author{
Qiaowei Li, Tianhui Zhang \\ Academy of Music, Hengyang Normal University, Hengyang City, \\ Hunan Province, 421002, China
}

\begin{abstract}
With the development of Internet and multimedia technology, the spread of traditional opera has undergone tremendous changes. The Internet and multimedia communication of Chinese opera is a new trend in the development of modern opera, and it is also an inevitable requirement for the opera to adapt to the development of contemporary society. Compared with the traditional opera stage communication, the audience structure of post stage period drama transmission is more abundant. Based on the author's research results, this paper put forward the modes of drama Communication in the post stage period from the aspects of TV and Internet.

Keywords: Post stage period; Drama; Communication; TV; Internet
\end{abstract}

\section{Introduction}

Taking into account the change of the carrier, the current opera communication has entered the post stage period. With the help of TV and Internet, a series of modern electronic media can spread traditional opera, and its history can be roughly from the beginning of the film into our country to the beginning of twentieth Century[1]. The spread of traditional opera has never been a single, and the drama communication in the post stage period is showing a more distinct multi level. First, opera is not only an art from the perspective of the composition of traditional opera, but it is composed of actors, audience, art performances, music, choreography and other multiple elements. Second, from the perspective of the the function carrier, the modern media developed on the basis of electronic 
technology can not only record the stage performance of the opera, show the opera art and reflect the cultural phenomenon, but also use their own unique technical means to re create the art of opera. Based on the unique content structure and the multi functional features of modern media, the opera spread in the post stage period has got a rapid development.

\section{The application of TV in the communication of traditional opera}

\subsection{The development of drama TV}

With the development of the TV industry and the increase of the demand for entertainment, the establishment of the opera and professional channels has a realistic basis. The establishment of Chinese opera columns and professional channels has opened up a new field for the spread of traditional Chinese opera in TV. For example, in order to promote and protect local folk traditional culture, Henan TV station actively founded the famous column opera Liyuanchun, which has enriched people's spiritual and cultural life achieved economic and social benefits. Liyuanchun experience is worth learning and reference[2].

With the advent of the era of audience segmentation, channel specialization has become one of the important trends in the development of TV media. CCTV channel eleven is the representative of the opera professional channel. CCTV channel eleven is a professional channel launched by CCTV, and it has become an important platform for the dissemination of traditional culture of TV drama in the past 10 years. 2004, CCTV channel eleven landed in Europe and North America, and then the TV drama program opens a window to the world. Relying on the television technology, all kinds of professional and non professional opera performances can break through the traditional mode of performance, and use of modern media technology can strengthen the opera from interaction between the actor and the examination, so it has become the effective means to promote the development of opera and communication. In addition, the rich drama audio and video products can also be seen as a natural derivative of the TV drama, which greatly facilitates the transmission of the opera.

\subsection{Characteristics of drama TV}

Spreading and carrying forward the opera art is the advantage of the TV drama program. Before the popularity of television, there is no media can be so rich, flexible, comprehensive to display the charm of opera art, and it is also one of the most important developments compared with traditional Chinese opera. The spread and popularization of opera education and opera culture from multi angles and multi layers are the characteristics of TV drama program[3]. Whether it is the famous interview or the name of the teaching, whether the opera knowledge introduction or opera stories of interpretation, whether it is the fans show or expert reviews, the TV drama program starts to make it easier for people to 
understand the traditional opera and opera culture. The broadcast of the TV drama program makes the audience appreciate the opera very convenient, or even a part of life at home. At the same time, the TV programs broadcast drama or opera performances, and most of them are high quality products or famous masterpieces, but it is impossible for the vast majority of the audience in real life. In the face of the TV drama program, the acceptance of the audience has changed a lot, which is mainly manifested in the characteristics of life and individuation. With the rapid popularization of television, it has become one of the most commonly used means of most people to obtain the necessary information by watching television programs. For the audience of TV drama program, watching TV drama is a part of life. However, the difference between going to the theatre or going to the cinema, the acceptance of drama has changed from collective to individual[4]. In addition to being alone, there are a lot of similarities between the audience of tv and the audience of traditional opera. They are the art of opera audience segmentation, they are a relatively stable group and the art of opera faithful watchmen.

\section{The Application of Internet in the Communication of Traditional Opera}

The active use of the new media in the spread of the opera is also reflected in the Internet world. Along with the fast development of the Internet, many opera websites is more and more. The opera website is a platform for the dissemination and exchange of opera and opera information, which is constructed by the Internet technology. Online opera resources come from all corners of the Internet, and its unprecedented level is abundant. The richness of online opera resources is also reflected in the Internet for other media compatibility and cross. Radio, film, television, books, periodicals, newspapers, government, collective, individual and so on can publish relevant information through their own website, can also publish information, discussion and contention on other sites.

The Internet has opened up a new world for the popularization of opera culture and the transmission of traditional opera. The spread of traditional opera on the Internet provides a great choice for the audience. Compared with the previous complex theatrical performances, network drama communication can highlight the position of the audience in the pass by activities. If the TV drama program can be compared to the "package", online drama spread can be called opera buffet. Through the Internet resources, opera audience can achieve a revolution from the "let me see the play" to "I want to see the play", which has really opened the era of people-oriented market.

At present, the opera website should do is to keep up with the times and improve themselves, to expand the impact of the site in the theater, film, television and other opera audience groups. Based on the premise of the audience, to do a further development for other edge audience groups[5]. The second is to focus on the site's own media advantages. If the spread of TV drama can reflect the multi 
integration of opera resources to some extent, the spread of network drama can highlight the active status of the audience. Opera website should focus on the unique advantages of the article to do a good job.

\section{A Reflection on the Spread of Drama in the Post Stage Period}

The popularity of the opera and the characteristics of popularization has decided the the inevitable choice of Chinese opera in mass media. The comprehensiveness of traditional opera art and the integration of modern mass media is basically the same. The mass media has provided a wealth of opera products but also limits the scope of the audience. The production communication mode of mechanization and electronic greatly facilitates the transmission of traditional opera, improves the speed and quality of the spread of traditional opera art, but it is not conducive to the innovation and development for the opera. The guiding role of mass media in the development of Chinese opera can not be ignored. In the rapid development of the times, people's values and aesthetic concepts are constantly changing. Fast food culture is increasingly prominent in people's daily cultural consumption[6]. Facing the acceleration of the pace of life and the change of people's aesthetic needs, the opera itself should adapt to the development of the times, and actively adjust themselves. There are many different forms in the form of traditional Chinese opera and fast food culture. The rich traditional cultural connotation in the form of traditional opera entertainment puts forward the corresponding requirements for the audience of the opera, which is contrary to the traditional culture education under the tide of commodity[7].

\section{Conclusion}

In short, for someone does not understand the play, it is difficult to let him become drama fans. Of course, with the development of traditional culture, the revival and popularization of Chinese culture research and education, we believe that the audience will grow stronger. As a kind of cultural entertainment, if drama wants to keep youth, it must constantly innovate. The change and development of opera is the challenge and requirement of the times. Innovation and advancing with the times should be the basic principles of the development of opera. The deep research of the opera art law provides an important reference for the transformation of the opera. In the near future, the mature cultural market, the scientific communication operation mechanism, high-quality team and audience will form a good ecological environment, and become an important part of the construction of advanced culture. 


\section{Acknowledgement}

The research was supported by the following items:

(1) Project of Hunan Province social science achievement evaluation committee: The Real Dilemma of Hunan Flower Drum Song and its Innovation and Development(Number XSPYBZZ002).

(2) Project of Hengyang City Social Science Fund: The Inheritance Strategies of Hengyang Music Culture in Local College Music Education(Number 2015D121). (3) Project of Hengyang City Social Science Fund: Hengyang City music culture from the perspective of Ecotourism - A Case Study based on Hengzhou Flower Drum Song(Number 2015D083).

\section{References}

[1] Di Hanwei. Drama across the Internet. National Art Research, (03), pp.22-27, 2016.

[2] Chen Ying. Analysis of drama and film creation under the background of new media. New Media Research, (07), pp.44-46

[3] Pan Kewu. Weapons on the TV drama as a medium of art. Henan Social Sciences, (08), pp.66-70, 2014.

[4] Wang Xuemei. A study on the value of drama in the context of cultural communication. Sichuan Drama, (01), pp.88-91, 2013.

[5] Zeng Yi, Cao Hongliang. Ancient drama communication aesthetics and modern communication art. Chongqing Social Sciences, (01), pp.60-66, 2009.

[6] Wang Yue. Some views on TV drama. Beauty and Times, (05), pp.114-117, 2007.

[7] Wang Tingxin. The study of the Internet and the spread of traditional Chinese opera. Sichuan Drama, (07), pp.101-118, 2004. 